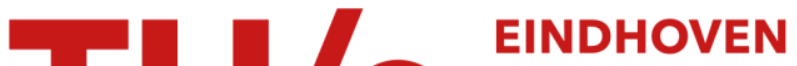 UNIVERSITY OF TECHNOLOGY
}

\section{A bioreactor to identify the driving mechanical stimuli of tissue growth and remodeling}

Citation for published version (APA):

van Kelle, A. J., Oomen, P. J. A., Bulsink, J. A., Janssen - van den Broek, W. J. T., Lopata, R. G. P., Rutten, M. C. M., Loerakker, S., \& Bouten, C. V. C. (2017). A bioreactor to identify the driving mechanical stimuli of tissue growth and remodeling. Tissue Engineering. Part C: Methods, 23(6), 377-387.

https://doi.org/10.1089/ten.tec.2017.0141, https://doi.org/10.1089/ten.TEC.2017.0141

DOI:

10.1089/ten.tec.2017.0141

10.1089/ten.TEC.2017.0141

Document status and date:

Published: 01/06/2017

Document Version:

Author's version before peer-review

Please check the document version of this publication:

- A submitted manuscript is the version of the article upon submission and before peer-review. There can be important differences between the submitted version and the official published version of record. People interested in the research are advised to contact the author for the final version of the publication, or visit the $\mathrm{DOI}$ to the publisher's website.

- The final author version and the galley proof are versions of the publication after peer review.

- The final published version features the final layout of the paper including the volume, issue and page numbers.

Link to publication

\section{General rights}

Copyright and moral rights for the publications made accessible in the public portal are retained by the authors and/or other copyright owners and it is a condition of accessing publications that users recognise and abide by the legal requirements associated with these rights.

- Users may download and print one copy of any publication from the public portal for the purpose of private study or research.

- You may not further distribute the material or use it for any profit-making activity or commercial gain

- You may freely distribute the URL identifying the publication in the public portal.

If the publication is distributed under the terms of Article $25 \mathrm{fa}$ of the Dutch Copyright Act, indicated by the "Taverne" license above, please follow below link for the End User Agreement:

www.tue.nl/taverne

Take down policy

If you believe that this document breaches copyright please contact us at:

openaccess@tue.nl

providing details and we will investigate your claim. 


\section{A Bioreactor to Identify the Driving Mechanical Stimuli of Tissue Growth}

\section{and Remodeling}

Mathieu A.J.van Kelle ${ }^{1,2}$, MSc; Pim J.A. Oomen ${ }^{1,2}$, MSc; Jurgen A. Bulsink ${ }^{1}$; Marloes W.J.T. Janssen-van den Broek ${ }^{1,2}$; BSc, Richard G.P. Lopata ${ }^{1}$, PhD; Marcel C.M. Rutten ${ }^{1}$, PhD; Sandra Loerakker ${ }^{*} *^{1,2}$, PhD; Carlijn V.C. Bouten ${ }^{1,2}$, PhD

* These authors contributed equally to this work

** Corresponding author

1. Department of Biomedical Engineering, Eindhoven University of Technology, Groene Loper, Building 15, Gemini-Zuid, 5612 AP, Eindhoven, The Netherlands

2. Institute for Complex Molecular Systems, Eindhoven University of Technology, De Zaale, 5612 AJ Eindhoven, The Netherlands

Mathieu A.J. van Kelle: a.j.v.kelle@tue.nl, T: 0031040247 5415, F: 00310402434970

Pim J. A. Oomen: p.j.a.oomen@tue.nl, T: 0031040247 5415, F: 00310402434970

Jurgen A. Bulsink: j.a.bulsink@tue.nl, T: 0031040247 7397, F: 00310402434970

Marloes W.J.T. Janssen-van den Broek: W.J.T.Janssen-v.d.Broek@tue.nl, T: 0031040247 2797, F: 0031040243 4970

Richard G.P. Lopata: r.lopata@tue.nl, T: 0031040247 4878, F: 00310402434970

Marcel C.M. Rutten: m.c.m.rutten@tue.nl, T: 0031040247 2789, F: 00310402434970

Sandra Loerakker: s.loerakker@tue.nl, T: 0031040247 3048, F: 00310402434970

Carlijn V.C. Bouten: c.v.c.bouten@tue.nl, T: 0031040247 3006, F: 00310402434970 


\section{Abstract}

Tissue growth and remodeling are essential processes that should ensure long-term functionality of tissue engineered (TE) constructs. Even though it is widely recognized that these processes strongly depend on mechanical stimuli, the underlying mechanisms of mechanically-induced growth and remodeling are only partially understood. It is generally accepted that cells sense mechanical changes and respond by altering their surroundings, by means of extracellular matrix (ECM) growth and remodeling, in an attempt to return to a certain preferred mechanical homeostatic state. ${ }^{1,2}$ Yet, the exact mechanical cues that triggers cells to synthesize and remodel their environment remain unclear.

To identify the driving mechanical stimuli of these processes, it is critical to be able to temporarily follow the mechanical state of developing tissues under physiological loading conditions. Therefore, a novel 'versatile tissue growth and remodeling' (Vertigro) bioreactor was developed that is capable of tissue culture and mechanical stimulation for a prolonged time period, while simultaneously performing mechanical testing. The Vertigro's unique two-chamber design allows easy, sterile handling of circular 3D TE constructs in a dedicated culture chamber, whilea separate pressure chamber facilitates a pressuredriven dynamic loading regime during culture. As a proof-of-concept, temporal changes in the mechanical state of cultured tissues were quantified using non-destructive mechanical testing by means of a classical bulge test, in which the tissue displacement was tracked using ultrasound imaging. To demonstrate the successful development of the bioreactor system, compositional, structural, and geometrical changes were qualitatively and quantitatively assessed using a series of standard analysis techniques.

With this bioreactor and associated mechanical analysis technique, a powerful toolbox has been developed to quantitatively study and identify the driving mechanical stimuli of engineered tissue growth and remodeling. 


\section{Introduction}

Cardiovascular tissues are known to adapt in response to changes in their environment through growth and remodeling. While the underlying mechanisms that govern growth and remodeling are not completely understood, it is well accepted that they are at least partly driven by mechanical cues. Cells residing in these tissues are capable of sensing mechanical cues, and as a response regulate their own behavior (e.g. proliferation) and the surrounding matrix by growth (increase in tissue mass) and remodeling (changes in tissue structure). It is believed that these processes occur to maintain a cellmediated mechanical homeostasis ${ }^{1,2}$. Yet, the mechanisms through which this mechanical homeostasis is maintained remain largely unknown. An improved knowledge of these mechanisms is key to better understand pathologies where adverse growth and remodeling occur, such as dilated and hypertrophic cardiomyopathy $^{3}$, valvular disease $e^{4,5}$, and aneurysm formation ${ }^{6,7}$. Moreover, a fundamental understanding of growth and remodeling is essential in the fields of regenerative medicine and tissue engineering.

In order to unravel the mechanisms of growth and remodeling, a systematic investigation of the underlying processes and associated mechanical parameters is required. To this end, bioreactor systems are valuable for studying the response of soft tissues to mechanical stimuli at the cellular and the tissue level. Initially, bioreactor systems were developed to study the effects of mechanical stimuli under static conditions. ${ }^{5,8-10}$ As cardiovascular tissues are mainly exposed to dynamic loading conditions, other bioreactors applied dynamic deformation to the tissue engineered (TE) constructs. ${ }^{11-16}$ For example, Rubbens et al. and Gould et al. applied cyclic strain to study the remodeling of 3D TE constructs. ${ }^{14,16}$ Moreover, Engelmayer et al. tested different scaffold candidates for heart valve tissue engineering by designing a bioreactor capable of applying cyclic flexure and laminar flow. ${ }^{11}$ In addition, several straindriven bioreactors have been proposed applying physiological mechanical and electrical stimulation to cardiac tissues. ${ }^{17}$ Finally, Kortsmit et al. introduced a bioreactor with a feedback system, to attain a 
constant maximal deformation while culturing TE heart valves in vitro. ${ }^{15}$ Yet, for cardiovascular tissues in vivo deformation is mainly governed by hemodynamic flow and pressure, which are known to play an important role in tissue growth and remodeling. ${ }^{18}$ To incorporate hemodynamic loading, Shaikh et al. and Hollweck et al. mimicked in vivo loading conditions, by using pulsatile bioreactors that applied physiological pressures to TE constructs. ${ }^{19,20}$

The previously mentioned bioreactors lacked two main features to study mechanically-driven growth and remodeling over time. First, these systems were not capable of tissue culture and mechanical stimulation for a prolonged time period, while simultaneously performing mechanical testing. Consequently, changes in the mechanical state of tissues with time could not be assessed for individual samples. Moreover, these systems did not retain a (dynamic) pressure during culture, which resembles the physiological load of many, primarily cardiovascular, tissue types, and can lead to a different adaptation mechanism of these tissues compared to displacement-controlled mechanical stimulation. Particularly, when applying a constant pressure during culture, the strain will not necessarily remain constant over time. Consequently, a strain-driven bioreactor may not capture the in vivo loading conditions and hence growth and remodeling phenomena.

The goal of the present study was to design and test a bioreactor that is capable of tissue culture and mechanical stimulation for a prolonged time period, while simultaneously performing mechanical testing. The bioreactor features a two-chamber design that allows easy and sterile handling of a TE construct, resembling thin cardiovascular tissues such as arteries and heart valves, in a dedicated culture chamber, while a second pressure chamber applies a physiologically relevant dynamic pressure regime, regulated by a custom-made feedback system.A novel non-destructive mechanical testing method is employed, involving a bulge test which can be performed inside the bioreactor, in which the construct's curvature is determined by ultrasound (US) imaging. This technique can be used to quantify temporal 
changes in tissue mechanical properties, without sacrificing the sample. Additional microscopy measurements of tissue thickness and prestretch serve to obtain the tissue geometry. Finally, confocal microscopy, histology and biochemical assays allow for determining tissue composition and architecture.

\section{Methods}

\subsection{Vertigro Bioreactor}

The 'versatile tissue growth and remodeling' (Vertigro) bioreactor consists of two chambers: a pressure chamber (bottom) and a detachable culture chamber (top) (Fig. 1) in which a TE construct is cultured. This design was chosen in order to have a separate chamber for sterile tissue culture and medium changes, while the other chamber is dedicated to applying the dynamic pressure. Both chambers are made of polysulfone (PSU, Röchling, Mannheim, Germany) and have connection ports fitting standard Iuer-lock slip tips. After sealing both chambers with a silicone membrane, the culture chamber is secured on top of the pressure chamber by means of three metal clamps. In this configuration, the two silicone membranes form a double membrane connection between the two chambers to ensure the transmission of pressure from the pressure chamber to the culture chamber.

The pressure chamber is connected to a pump containing a flexible silicone tube, which can be compressed with pressurized air. A proportional pneumatic valve (Festo, Esslingen Berkheim, Germany) regulates the inflow of pressurized air, by opening in accordance to a programmable waveform function, supplied by a multi-IO-card using LabVIEW software (National Instruments, Austin, TX, USA).

The culture chamber consists of a lower and an upper part, separated by an insert that is clamping the tissue construct. Both parts of the culture chamber are filled with culture medium. The top chamber is closed with a lid that allows free air exchange with the external environment, required to buffer the $\mathrm{pH}$ of the medium. Upon an increase in pressure in the pressure chamber, the membranes bulge into the 
culture chamber, pressurizing the tissue construct. A pressure sensor (P10EZ-1, BD|SENSORS, Thierstein, Germany) is connected to the lower part of the culture chamber to measure the pressure on the tissue in real-time.

A feedback system was implemented in the LabVIEW framework in order to keep the minimal and maximal pressures at preset levels. In case of deviations from this preset level ( $\pm 5 \%$ tolerance), either the offset (minimal pressure) or the amplitude (maximal pressure) of a square waveform function are changed accordingly, therefore maintaining a constant peak pressure during culture. The Vertigros, pressure sensors and pumps can be placed in an incubator $\left(37 \mathrm{C}^{\circ}, 100 \% \mathrm{RH}\right.$ and $\left.5 \% \mathrm{CO}_{2}\right)$, while the proportional air valves, pressure modules, and other hardware remain outside.

\subsection{Cell and tissue culture}

Tissue constructs were engineered using vascular derived cells, previously characterized as contractile, matrix-producing myofibroblasts, ${ }^{21}$ harvested from the human vena saphena magna according to the Dutch guidelines for secondary use of materials. Cells were expanded until passage 7 using culture medium containing advanced Dulbecco's Modified Eagle Medium (DMEM, Invitrogen, Carlsbac, CA, USA), supplemented with 10\% Fetal Bovine Serum (FBS, Greiner Bio One, Frinckenhausen, Germany), 1\% Glutamax (Invitrogen) and 1\% penicillin/streptomycin (Lonza, Basel, Switserland), with medium changes twice a week.

Prior to seeding, rapidly degrading non-woven polyglycolic acid (PGA) Biofelt (Biomedical Structures, Warwick, USA, $0.5 \mathrm{~mm}$ thickness, $70 \mathrm{mg} / \mathrm{cm}^{2}$ density) was cut to size to fit inside the inserts. To provide a slow-degrading fixation of the tissue on the edge of the insert, a polycaprolactone scaffold (PCL, electrospun in-house, thickness $0.25 \mathrm{~mm}$ ) was cut to the same diameter as the PGA scaffolds, while a circular $13 \mathrm{~mm}$ cutout was made in the center. Next, the PGA was coated with poly-4hydroxybutyrate (P4HB, Tepha, MA, USA) and mounted together with the PCL rings into the bioreactor inserts. The inserts 
were then immersed in 70\% ethanol for $30 \mathrm{~min}$. After sterilization, the inserts were washed with PBS and placed in $0.25 \mathrm{mg} / \mathrm{ml} \mathrm{L-ascorbic} \mathrm{2-phosphate} \mathrm{acid} \mathrm{(Sigma-Aldrich,} \mathrm{St.} \mathrm{Louis,} \mathrm{MO,} \mathrm{USA)} \mathrm{supplemented}$ standard culture medium (TE medium) overnight at $37 \mathrm{C}^{\circ}$ and $5 \% \mathrm{CO}_{2}$. The next day, the cells were seeded onto the scaffolds $\left(15 \times 10^{6}\right.$ cells $\left./ \mathrm{cm}^{3}\right)$ using fibrin as a cell carrier. ${ }^{22}$ Finally, the constructs were cultured statically for three weeks in 6-well plates in TE medium (which was changed three times a week). After this period, the constructs were strong enough to be cultured dynamically.

\subsection{Experimental protocol}

To assess bioreactor functional ity and to evaluate the proposed analysis techniques, a proof-of-principle experiment was performed (Fig. 2). In this experiment, 20 tissue constructs were cultured: In the first three weeks these were cultured statically, taking out four samples at the end of each week. From the remaining eight constructs, four were cultured under static conditions for one additional week, whilst the other four samples were cultured under dynamic loading conditions (minimal pressure $0 \mathrm{kPa}$, maximal pressure $2 \mathrm{kPa}$, frequency $1 \mathrm{~Hz}$ ).

\subsection{Analysis Techniques}

\subsubsection{Mechanical testing}

The bioreactor system was designed to perform mechanical testing via classical mechanical bulge tests without removing the constructs. A syringe was connected to the pressure chamber and placed in a Harvard pump (PHD2000, Harvard Apparatus, Holliston, MA, USA) to apply a volume-controlled pressure to the samples. The volume was gradually increased until a pressure of $2 \mathrm{kPa}$ was reached in the culture chamber. Subsequently, three pressure cycles were performed, of which the first two served as preconditioning cycles. An US transducer was mounted on top of the bioreactor, perpendicular to the sample surface, in order to nondestructively measure construct displacement as a function of pressure. Two-dimensional US imaging was performed with a MyLab70 US system (ESAOTE, Maastricht, NL), 
equipped with a linear array (LA523, center frequency of $7.5 \mathrm{MHz}$ ). The data were exported in video format (AVI) at a frame rate of $20 \mathrm{~Hz}$.

To quantify the mechanical behavior of the tissue, the in-plane stress was estimated as a function of stretch, assuming tissue isotropy. Tissue stretch was determined from the frames of the US movies (resolution $21.5 \mathrm{px} / \mathrm{mm}$ ) using a custom MATLAB script (MathWorks, Natick, MA, USA). In particular, for each frame, the tissue profile was detected using MATLAB's built-in edge detection function, through which a circle was fitted in the center region. The constrained tissue length $L_{0}$ at zero pressure and current tissue length $L$ in each consecutive frame were then obtained by calculating the circle's arc length. Additionally, tissue elongation, defined as the relative change of constrained length during culture time, was calculated as $L_{0}$ (at 0 pressure) divided by the initial construct diameter $(15.0 \mathrm{~mm})$. The in-plane stretch due to bulging $\lambda=L / L_{0}$ was then calculated as the change in length from the initial constrained sample length $L_{0}$ at zero pressure. Accounting for the presence of cell-induced tissue prestretch $\lambda_{p}$ (Section 2.3.2), a multiplicative decomposition was used to calculate the total elastic inplane tissue stretch $\lambda_{e}$ :

$$
\lambda_{e}=\lambda \lambda_{p}
$$

To estimate the mechanical state of the tissue, the Tension $T$ and Cauchy stress $\sigma$ in the in-plane direction of the construct were calculated using Laplace's law for a thin-walled shell:

$$
T=\frac{p}{2 \kappa} ; \sigma=\frac{p}{2 \kappa t}
$$

with $p$ the pressure, $\kappa$ the curvature and $t$ the deformed sample thickness. The curvature was calculated as the inverse of the fitted circle's radius. The deformed tissue's thickness was derived from the measured thickness $t_{0}$ (Section 2.3.3) and in-plane elastic stretch, assuming tissue isotropy and incompressibility: 


$$
t=\frac{t_{0}}{\lambda_{e}^{2}}
$$

\subsubsection{Prestretch}

Tissue prestretch was measured by calculating the change in surface area upon releasing the tissue constraints. Nine circular markers were placed in a $3 \times 3$ rectangular grid on each construct and positions were tracked using a high-resolution digital microscope (VHX-500, Keyence, Itasca, IL, USA) at a resolution of $100 \mathrm{px} / \mathrm{mm}$ and $20 \mathrm{x}$ magnification. Subsequently, tissues were released from their constraints by dissecting them from the sample holder using a cork borer with a diameter of $13.0 \mathrm{~mm}$ and a second image was recorded immediately. The surface area spanned by the markers was calculated for both images using a semi-automatic custom MATLAB script. The amount of tissue prestretch was then calculated in terms of surface area change, defined as the unconstrained surface area divided by the constrained surface area. The surface area change equals the squared length change $\lambda_{p}$, used in the previous section.

\subsubsection{Thickness}

After the prestretch measurements, all constructs were cut in half. Three high-magnification (100x) images using the VHX-500 digital microscope were taken perpendicular to the cutting edge of one of the two halves, with the three positions coinciding with the three markers that were placed at the sample cutting edge for the prestretch measurements. Using the microscope's complimentary software, the thickness $t_{0}$ was manually determined at 5 positions in each image.

\subsubsection{Collagen Orientation}

The tissues were stained with $\mathrm{CNA} 35^{23}$ to enable collagen visual ization. After a 1-hour incubation period, constructs were visualized using a confocal laser scanning microscope (TCS SP5X, Leica Microsystems, Wetzlar, Germany) with complimentary software (Leica Application Suite Advanced Fluorescence). A tile scan (magnification 10x, excitation $488 \mathrm{~nm}$, emission $520 \mathrm{~nm}$ ) was made to capture the gross collagen 
architecture of the entire tissue. Collagen fiber orientation was quantified by analyzing the individual images of each tile scan, using a custom MATLAB script, based on the work of Frangi et al.. ${ }^{24}$ which was previously used to quantify collagen orientation. ${ }^{25}$ For each tile scan, a histogram containing the fiber fraction per angle was obtained.

\subsubsection{Histology}

Constructs were fixed in $3.7 \%$ formaldehyde overnight, and subsequently embedded in paraffin and sectioned into slices of $7 \mu \mathrm{m}$. The slices were stained for Glycosaminoglycans (GAGs) and collagen using Alcian blue $(A B)$ and Picosirius red (PR), respectively. The stained sections were imaged using a brightfield microscope (Axio Observer Z1, Zeiss, Oberkoch, Germany) equipped with filters to provide polarized light illumination. Additionally, a fluorescent co-staining for collagen type $1, \alpha \mathrm{SMA}$ and cell nuclei was performed and visualized using an Axiovert 200M microscope (Zeiss).

\subsubsection{Biochemical assays}

Half of each construct was lyophilized overnight and subsequently digested using a papain digestion buffer at $60 \mathrm{C}^{\circ}$ for 16 hours. The total tissue dry weight was determined before and after digestion. Tissue GAGs were quantified using an adapted version of the protocol by Farndale et al ${ }^{26}$, together with a standard curve derived from chondroitin sulfate from shark cartilage (Sigma-Aldrich). Using the Hoechst dye method ${ }^{27}$ and a standard curve of calf thymus DNA (Sigma-Aldrich), the total DNA content was quantified. Finally, the total hydroxyproline content, a measure for the amount of collagen, was determined with a modification of the assay by Huszar et al.$^{28}$ and a standard curve derived from trans-4hydroxyproline (Sigma-Aldrich). Protein amounts were normalized with respect to the total tissue dry weight before digestion. 


\section{Results}

\subsection{Tissue culture in the Vertigro bioreactor}

All statically cultured tissues endured the entire culture period up to 4 weeks (Fig. 3). Throughout dynamic culture, the feedback system successfully applied and maintained the preset maximal and minimal pressures to the TE constructs (Fig.4). However, 2 out of 4 constructs that were cultured under dynamic loading conditions ruptured.

\subsection{Mechanical Testing}

The tissue profile was successfully tracked via ultrasound imaging (Fig. 5). Also, the mechanical tests were performed for all four samples in week 3, showing similar tension-pressure relationships (Fig. 6A) and nonlinear stress-stretch behavior in all samples (Fig. 6C). During week 4, testing of two statically cultured constructs failed due to sample leakage and the presence of a fold in the tissue construct, respectively. The two successfully measured samples showed similar tension-pressure and stress-stretch behavior, featuring a higher extensibility and lower stiffness compared to week 3 (Fig. 6B,D). For 1 of the 2 dynamically cultured samples, the ultrasound signal was too weak to be processed, potentially due to the low thickness of this sample. A nonlinear stress-stretch curve was observed for the successfully measured sample (Fig. 6D).

\subsection{Elongation}

Comparing tissue elongation (constrained tissue length at 0 pressure divided by initial construct diameter), there was a clear difference between the statically and dynamically cultured samples. Where the static sample tissue length was similar to the initial construct diameter $(1.01 \pm 0.01)$, the dynamic samples did show elongation (1.07 \pm 0.00$)$ (Fig. 7A). 


\subsection{Prestretch}

Tissue prestretch was hardly observed after one week of static culture (1.01 \pm 0.01$)$ but increased with static culture time. At week 4, the area prestretch was slightly higher for the dynamically cultured

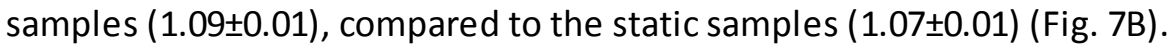

\subsection{Thickness}

From the original scaffold thickness of $500 \mu \mathrm{m}$, tissue thickness decreased more than $50 \%$ within the first week of culture to $226 \pm 48 \mu \mathrm{m}$ (Fig. 7C). Subsequently, tissue thickness further decreased to a value of $\sim 150 \mu \mathrm{m}$ after which only minor changes occurred.

\subsection{Collagen Orientation}

After staining with CNA, collagen fibers could be clearly observed in the tissue samples (Fig. 8A). Analysis of the fiber architecture showed an in-plane fiber distribution with no clear preferred directionality, for all tissue samples, for the entire culture period (Fig. 8B-F).

\subsection{Histology}

The AB and hematoxylin (Fig. 9A-E) and PR red (Fig. 9F-J) staining show homogeneously distributed cells, GAGs and collagen fibers in all tissues. The collagen fibers were mainly aligned in the tissue plane and, with time, collagen fibers were observed to become thicker (Fig. 9K-O). Finally, the fluorescence images (Fig. 9P-T) show vast amounts of $\alpha$ SMA-positive cells (green), indicating the presence of contractile cells.

\subsection{Biochemical Assays}

The total tissue dry weight of the statically cultured samples appeared relatively constant with culture time (Fig. 10A). However, since the amount of PGA scaffold decreases with time, these results indicate an increase in tissue mass with time. At week 4, the dynamically cultured samples appeared to have a lower dry weight compared to the statically cultured samples. 
Both the dry weight content of GAGs and hydroxyproline increased with time (Figs. 10B and C). The dynamically cultured samples contained a higher fraction of GAGs, and a slightly lower fraction of hydroxyproline compared to the static samples at week 4. The concentration of DNA increased up to week 3 , and marginally dropped in week 4 for the static samples and more considerably for the dynamic samples (Fig. 10D). 


\section{Discussion}

In the present study, a novel bioreactor and associated analysis techniques were developed to systematically investigate the synergy between mechanics and tissue growth \& remodeling. A proof-ofprinciple experiment was conducted to demonstrate the proposed framework's potential.

\subsection{Vertigro functionality}

The Vertigro is a versatile bioreactor capable of dynamically culturing planar TE constructs, and simultaneously performing mechanical testing. Its unique two-chamber design allows easy and sterile handling of the tissue construct, while the dedicated bottom pressure chamber attains the pressure application. In addition, although not treated in the present study, the construct geometry can be easily changed by using removable inserts with different designs to mount tissue constructs with different geometries inside the bioreactor. The design in which currently rapidly degrading circular PGA scaffold was combined with slow degrading PCL scaffold, proved to be successful for culturing TE constructs that did not detach due to developing cell tension during static culture. Finally, the custom-made feedback system maintained the preset pressures during dynamic culturing, demonstrated here for a one-week period.

\subsection{Tissue composition and architecture}

Histological analysis (Fig. 9) showed the presence of GAGs, collagen fibers and $\alpha$ SMA positive cells in the tissue constructs. These findings were quantitatively confirmed by biochemical assays (Fig. 10), demonstrating that tissue dry weight remained fairly constant, where the fraction PGA scaffold was gradually substituted by cell-produced matrix components such as collagen and GAGs. Finally, CNAstained samples confirmed the presence of vast amounts of isotropically oriented collagen fibers (Fig. 8), in line with the homogeneous pressure application and isotropic boundary conditions and scaffold properties. 


\subsection{Tissue geometry}

Besides changes in tissue composition, the geometry of the constructs underwent notable changes (Fig. 3). First, tissue thickness in week 1 was halved compared to the original scaffold thickness, gradually decreasing to a constant thickness of $\sim 150 \mu \mathrm{m}$. The large initial decrease in thickness is probably due to the high PGA porosity, which decreases immediately upon seeding. The consecutive decrease in thickness can be attributed to developing cell contractility that leads to tissue compaction in the unconstrained directions. These results are in line with the prestretch measurements that show an increase in prestretch with culture time, corresponding with previous observations ${ }^{10}$ and the $\alpha \mathrm{SMA}$ positive cells observed via histology. Besides changes in thickness, the dynamically cultured samples were longer when constrained compared to their statically cultured counterparts. However, in contrast to the observed increase in unloaded length, the biochemical assays showed that the weight of the dynamic samples was lower compared to the static samples. This phenomenon may be explained by the fact that the amount of GAGs in the dynamic samples was higher compared to the static samples. The highly polar GAGs retain vast amounts of water and therefore increase tissue volume, which is not taken into account in the dry weight measurements.

\subsection{Tissue mechanics}

The bioreactor was designed to not only culture tissue samples for a prolonged time period, but also to simultaneously perform mechanical testing, by means of a classical mechanical bulge test $\mathrm{t}^{29,30}$. This test can be performed non-destructively as the mechanical test is performed inside the bioreactor itself, while measuring the tissue deformation non-destructively using ultrasound. The stress-stretch relationships of all samples (Fig. 6C,D) showed the typical exponential nonlinear behavior featured in collagenous soft tissues. Furthermore, the prestretch measurements are essential when analyzing the tissue mechanics: not taking the tissue prestretch into account can lead to a significant overestimation of the tissue stiffness, dependent on the degree of prestretch. ${ }^{31}$ 


\subsection{Limitations}

The use of ultrasound to measure tissue deformation during mechanical testing provides a great advantage of nondestructive testing. In fact, the suitability of ultrasound imaging to measure in vitro material functionality was recently demonstrated. ${ }^{32}$ Nevertheless, the limited spatial resolution of the current US system and method used resulted in inaccuracies in estimating tissue thickness, which was therefore measured using microscopy in the present study. The spatial resolution can be improved by using a higherfrequency ultrasound transducer and utilize the tracking of raw radio-frequency signals, allowing for non-destructive determination of tissue thickness, and high-precision tracking of the

tissue. ${ }^{33}$ Moreover, in the present study the stresses were estimated using Laplace's law, which is only valid for true membranes. In order to accurately estimate the mechanical properties in case of thick tissues, the use of an inverse finite element analysis method is recommended.

All of the 16 statically cultures samples were successfully cultured and analyzed. However, 2 of the 4 dynamically cultured samples failed in week 4. To prevent future loss of samples during dynamic culture, a smoother pressure gradient could be implemented. Currently, a square waveform function was used, but a sinoid function would lead to a smoother pressure transition. Additionally, a slow-degrading scaffold, rather than the rapidly-degrading PGA, can be used to support the tissue, which could shorten the current static culture time of three weeks that is required before the tissue construct is strong enough to withstand dynamic pressure.

\subsection{Conclusions and outlook}

In conclusion, a novel versatile bioreactor was developed that offers a potent platform to unravel underlying mechanisms of tissue growth and remodeling through a systematic analysis of the influence of, amongst others, scaffold material, cell type and pressure regimens, on tissue (mechanical) adaptation. An improved knowledge of this process is key to deliver insights in pathologies where 
adverse growth and remodeling occur, and essential in the fields of regenerative medicine and tissue engineering.

This versatile framework allows for tissue culture and pressure-driven mechanical stimulation under hemodynamic loading while simultaneously performing mechanical testing without sacrificing samples. This allows for the monitoring of tissue samples with time and as such has great potential for investigating mechanically-induced growth and remodeling. Due to the versatile setup of the twochamber bioreactor,-permissive of sterile handling while maintaining dynamic pressure profiles-many different physiological situations can be studied in a well-controlled in vitro environment. This allows for a systematicinvestigation of how mechanical stimuli affect tissue adaptation, for example by changing the pressure regime, degree of tissue anisotropy, scaffold material, and construct geometry. To demonstrate the successful development of the bioreactor system, a wide range of standard analysis techniques was employed to analyze the developing tissue constructs. In future studies, the current set of techniques can be extended with e.g. an inverse finite element method to accurately estimate the evolution of the mechanical properties. 


\section{Acknowledgments}

We acknowledge the support from the Netherlands Cardiovascular Research Initiative (CVON 2012-01):

The Dutch Heart Foundation, Dutch Federation of University Medical Centers, the Netherlands Organization for Health Research and Development and the Royal Netherlands Academy of Sciences, and the European Union's Seventh Framework Programme (grant agreement No 604514). We also want to acknowledge the ICMS animation studio for the help with the design of the graphical abstract in figure 1.

\section{Author Disclosure Statement}

No competing financial interests exist.

\section{References}

1. Hoffman, B. D., Grashoff, C., and Schwartz, M. A. Dynamicmolecular processes mediate cellular mechanotransduction. Nature 475, 316, 2011.

2. Humphrey, J. D., Dufresne, E. R., and Schwartz, M. A. Mechanotransduction and extracellular matrix homeostasis. Nat Rev Mol Cell Biol 15, 802, 2014.

3. Frey, N., and Olson, E. N. Cardiac Hypertrophy: The Good, the Bad, and the Ugly. Annu Rev Physiol 65, 45, 2003.

4. Fisher, C. I., Chen, J., and Merryman, W. D. Calcific nodule morphogenesis by heart valve interstitial cells is strain dependent. Biomech Model Mechanobiol 12, 5, 2013.

5. Farrar, E. J., Pramil, V., Richards, J. M., Mosher, C. Z., and Butcher, J. T. Valve interstitial cell tensional homeostasis directs calcification and extracellular matrix remodel ing processes via RhoA signaling. Biomaterials 105, 25, 2016.

6. Martufi, G., and Gasser, T. C. Turnover of fibrillar collagen in soft biological tissue with application to the expansion of abdominal aortic aneurysms. J R Soc Interface 9, 3366, 2012.

7. Humphrey, J. D., Schwartz, M. A., Tellides, G., and Milewicz, D. M. Role of mechanotransduction in vascular biology: Focus on thoracic aortic aneurysms and dissections. Circ Res 116, 1448, 2015.

8. Legant, W. R., Pathak, A., Yang, M. T., Deshpande, V. S., McMeeking, R. M., and Chen, C. S. Microfabricated tissue gauges to measure and manipulate forces from 3D microtissues. Proc Natl 
Acad Sci U S A 106, 10097, 2009.

9. Hu, J. J., Humphrey, J. D., and Yeh, A. T. Characterization of engineered tissue development under biaxial stretch using nonlinear optical microscopy. Tissue Eng Part A 15, 1553, 2009.

10. van Vlimmeren, M. A. A., Driessen-Mol, A., Oomens, C. W. J., and Baaijens, F. P. T. Model System to Quantify Stress Generation, Compaction, and Retraction in Engineered Heart Valve Tissue. Tissue Eng Part C Methods 17, 983, 2011.

11. Engelmayr, G. C., Hildebrand, D. K., Sutherland, F. W. H., Mayer, J. E., and Sacks, M. S. A novel bioreactor for the dynamic flexural stimulation of tissue engineered heart valve biomaterials. Biomaterials 24, 2523, 2003.

12. Merryman, W. D., Lukoff, H. D., Long, R. A., Engelmayr, G. C., Hopkins, R. A., and Sacks, M. S. Synergistic effects of cyclic tension and transforming growth factor-ß1 on the aortic valve myofibroblast. Cardiovasc Pathol 16, 268, 2007.

13. Humphrey, J. D., Wells, P. B., Baek, S., Hu, J. J., McLeroy, K., and Yeh, A. T. A theoreticallymotivated biaxial tissue culture system with intravital microscopy. Biomech Model Mechanobiol 7, 323, 2008.

14. Rubbens, M. P., Driessen-Mol, A., Boerboom, R. A., Koppert, M. M. J., van Assen, H. C., TerHaar Romeny, B. M., Baaijens, F.P.T., and Bouten, C. V.C. Quantification of the Temporal Evolution of Collagen Orientation in Mechanically Conditioned Engineered Cardiovascular Tissues. Ann Biomed Eng 37, 1263, 2009.

15. Kortsmit, J., Rutten, M. C. M., Wijlaars, M. W., and Baaijens, F. P. T. Deformation-controlled load application in heart valve tissue engineering. Tissue Eng Part C Methods 15, 707, 2009.

16. Gould, R. A., Chin, K., Santisakultarm, T. P., Dropkin, A., Richards, J. M., Schaffer, C. B., and Butcher, J. T. Cyclic strain anisotropy regulates valvular interstitial cell phenotype and tissue remodeling in three-dimensional culture. Acta Biomater 8, 1710, 2012.

17. Stoppel, W. L., Kaplan, D. L., and Black, L. D. Electrical and mechanical stimulation of cardiaccells and tissue constructs. Adv Drug Deliv Rev 96, 135, 2016.

18. Humphrey, J. D. Vascular adaptation and mechanical homeostasis at tissue, cellular, and subcellular levels. Cell Biochem Biophys 50, 53, 2008.

19. Shaikh, F. M., O’Brien, T.P., Callanan, A., Kavanagh, E. G., Burke, P. E., Grace, P. A., and McGloughlin, T. M. New pulsatile hydrostatic pressure bioreactor for vascular tissue-engineered constructs. Artif Organs 34, 153, 2010.

20. Hollweck, T., Akra, B., Häussler, S., Uberfuhr, P., Schmitz, C., Pfeifer, S., Eblenkamp, M., Wintermantel, E., and Eissner, G. A novel pulsatile bioreactor for mechanical stimulation of tissue engineered cardiac constructs. J Funct Biomater 2, 107, 2011.

21. Mol, A., Rutten, M. C. M., Driessen, N. J. B., Bouten, C. V. C., Zünd, G., Baaijens, F. P. T., and Hoerstrup, S. P. Autologous Human Tissue-Engineered Heart Valves: Prospects for Systemic Application. Circulation 114, 152, 2006.

22. Mol, A., Van Lieshout, M. I., Dam-De Veen, C. G., Neuenschwander, S., Hoerstrup, S. P., Baaijens, 
F. P.T., and Bouten, C. V.C. Fibrin as a cell carrier in cardiovascular tissue engineering applications. Biomaterials 26, 3113, 2005.

23. Boerboom, R. A., Krahn, K. N., Megens, R. T. A., van Zandvoort, M. A. M. J., Merkx, M., and Bouten, C. V. C. High resolution imaging of collagen organisation and synthesis using a versatile collagen specific probe. J Struct Biol 159, 392, 2007.

24. Frangi, A. F., Niessen, W. J., Vinken, K. L., and Viergever, M. A. Multiscale Vessel Enhancement Filtering. Med Image Comput Comput Interv 1496, 404, 1998.

25. Oomen, P. J. A., Loerakker, S., Van Geemen, D., Neggers, J., Goumans, M. J. T. H., Van Den Bogaerdt, A. J., Bogers, A. J. J. C., Bouten, C. V.C., and Baaijens, F. P. T. Age-dependent changes of stress and strain in the human heart valve and their relation with collagen remodeling. Acta Biomater 29, 161, 2016.

26. Farndale, R. W., Buttle, D. J., and Barret, A. J. Improved quantitation and discrimination of sulphated glycosaminoglycans by use of dimethylmethylene blue. Biochim Biophys Acta 883, 173, 1986.

27. Cesarone, C. F., Bolognesi, C., and Santi, L. Improved microfluorometric DNA determination in biological material using 33258 Hoechst. Anal Biochem 100, 188, 1979.

28. Huszar, G., Maiocco, J., and Naftolin, F. Monitoring of collagen and collagen fragments in chromatography of protein mixtures. Anal Biochem 105, 424, 1980.

29. Hayashi, K. Experimental approaches on measuring the mechanical properties and constitutive laws of arterial walls. J Biomech Eng 115, 481, 1993.

30. Avril, S., Badel, P., and Duprey, A. Anisotropic and hyperelastic identification of in vitro human arteries from full-field optical measurements. J Biomech 43, 2978, 2010.

31. Rausch, M. K., and Kuhl, E. On the effect of prestrain and residual stress in thin biological membranes. J Mech Phys Solids 61, 1955, 2013.

32. Hurtado-Aguilar, L. G., Mulderrig, S., Moreira, R., Hatam, N., Spillner, J., Schmitz-Rode, T., Jockenhoevel, S., and Mela, P. Ultrasound for in vitro noninvasive, real time monitoring and evaluation of tissue-engineered heart valves. Tissue Eng Part C Methods 49, 974, 2016.

33. Lopata, R. G. P., Nillesen, M. M., Hansen, H. H. G., Gerrits, I. H., Thijssen, J. M., and de Korte, C. L. Performance evaluation of methods for two-dimensional displacement and strain estimation using ultrasound radio frequency data. Ultrasound Med Biol 35, 796, 2009. 


\section{Figures}
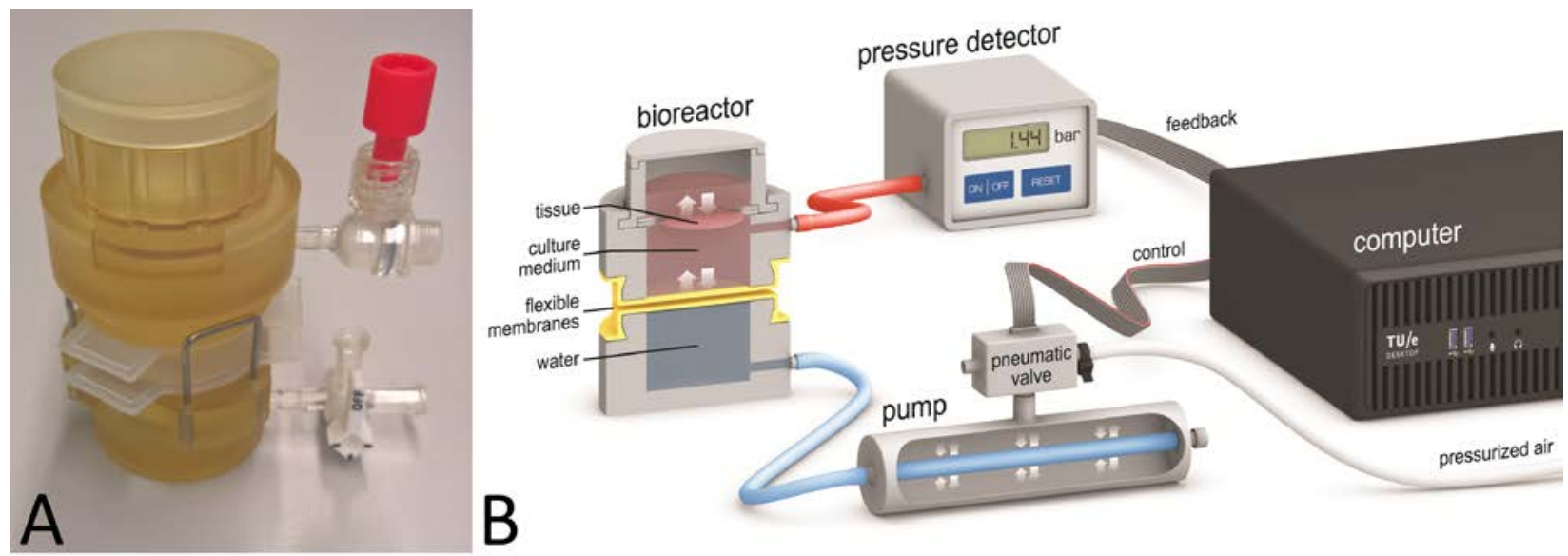

Fig. 1

FIG. 1. (A) The Vertigro bioreactor. (B) Schematic representation of the Vertigro Bioreactor and pressure application system.

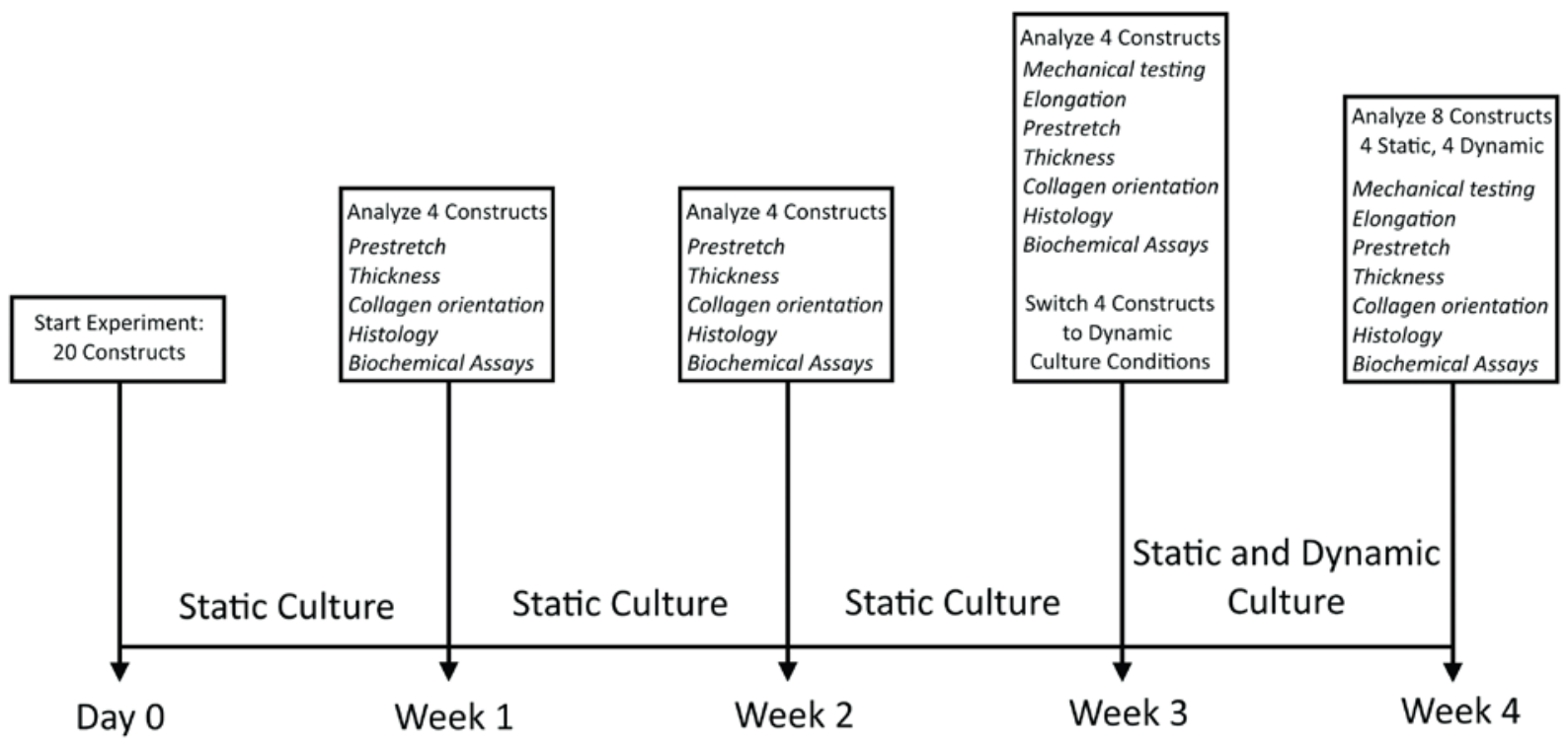

Fig. 2

FIG. 2. Timeline used for proof of concept experiment. 


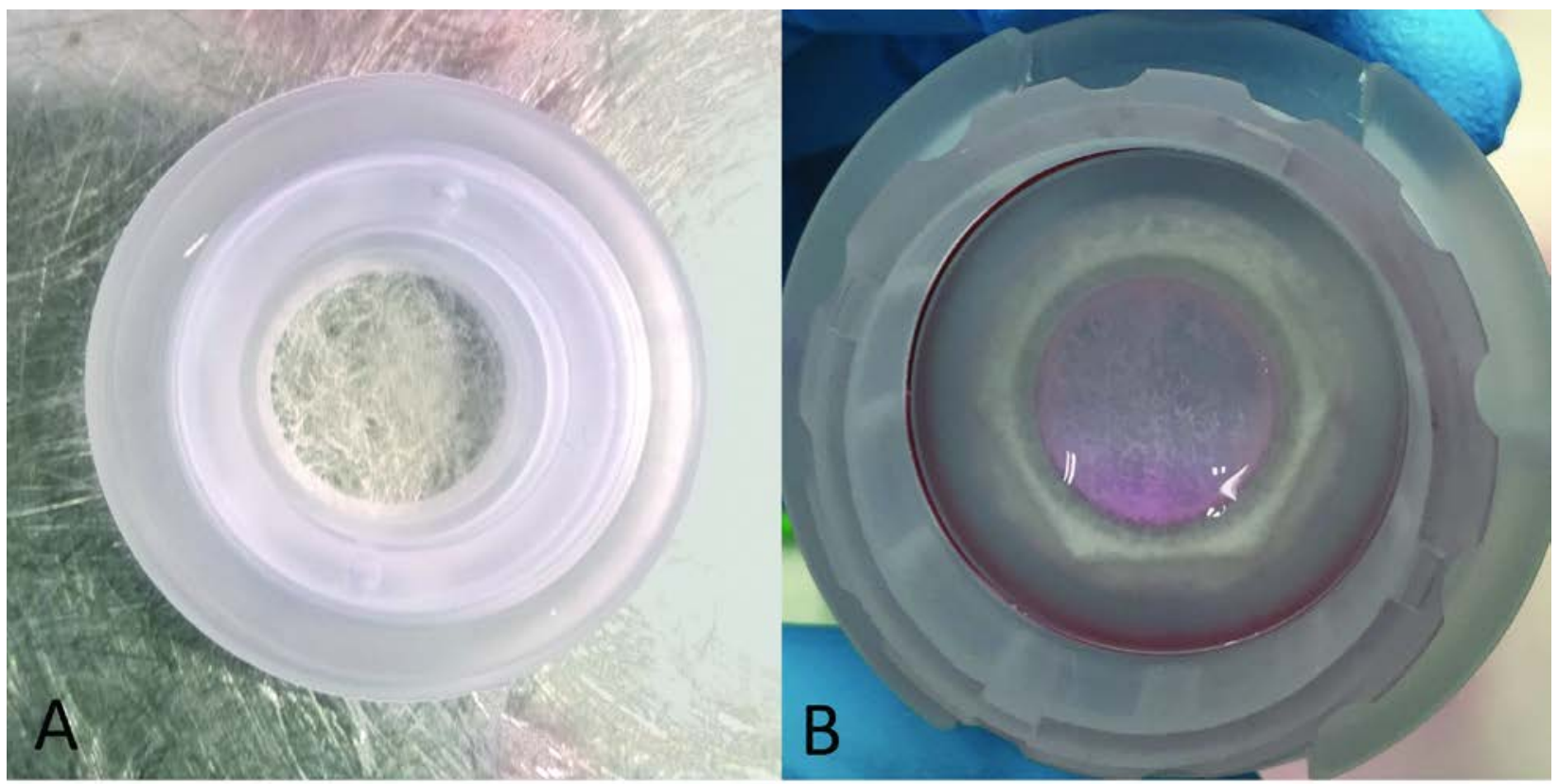

Fig. 3

FIG. 3. (A) Bioreactor insert with clamped scaffolds prior to seeding. (B) TE construct after 4 weeks of culture.
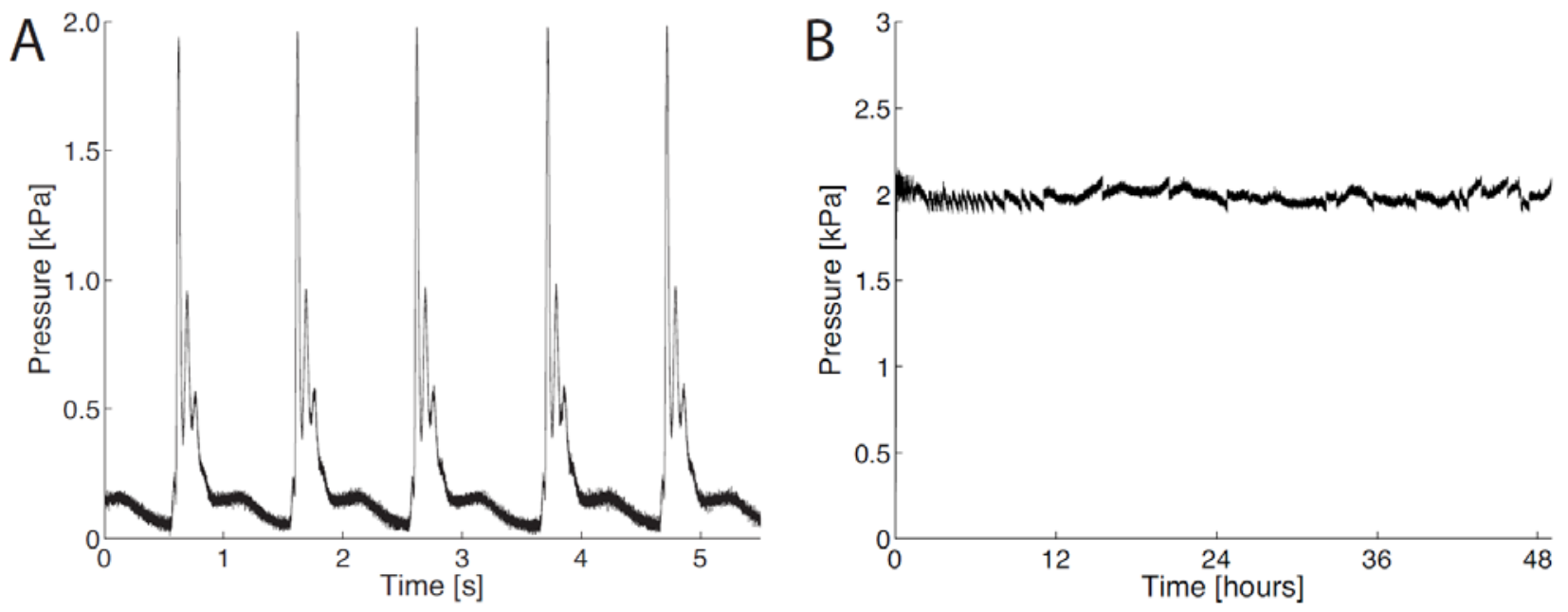

FIG. 4. (A) 5 Loading cycles of the TE constructs for a preset pressure of $2 \mathrm{kPa}$ and a frequency of $1 \mathrm{~Hz}$. (B) Average maximal pressure over a time period of 5 seconds, in between medium changes. 

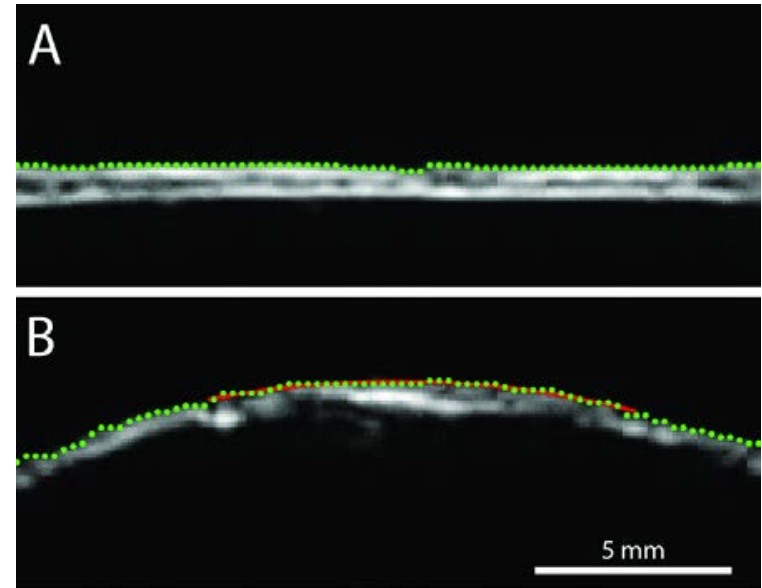

Fig. 5

FIG. 5. Ultrasound B-modes images of a 3-week-old sample in the (A) initial and (B) deformed

configuration. The sample profile was tracked (green dots) and a circle was fitted to the center region (red) to estimate the curvature.
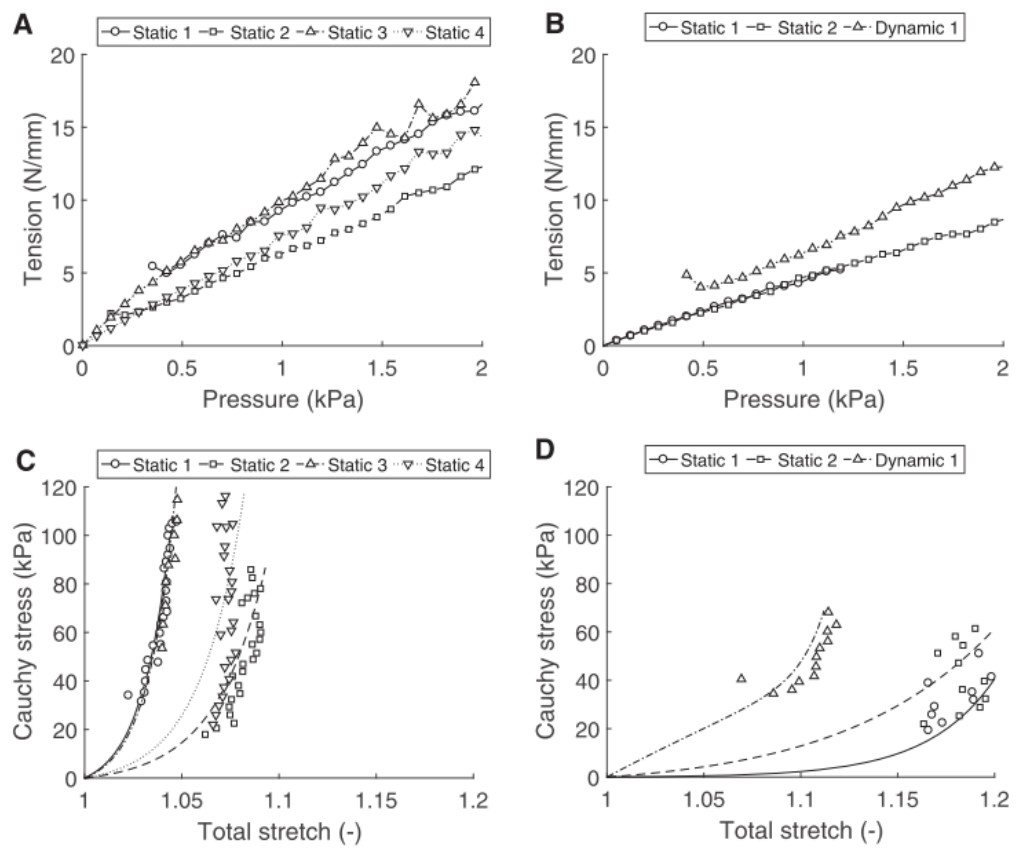

FIG. 6. Tension-pressure relations at (A) the end of 3 weeks of static culture in four samples and (B) after 4 weeks static culture and after 3 weeks static +1 week dynamic culture. Non-linear stress-stretch curves of 3-weeks statically cultured tissue samples (C) after 4 weeks of static culture and (D) after 3 weeks static +1 week dynamic culture. 

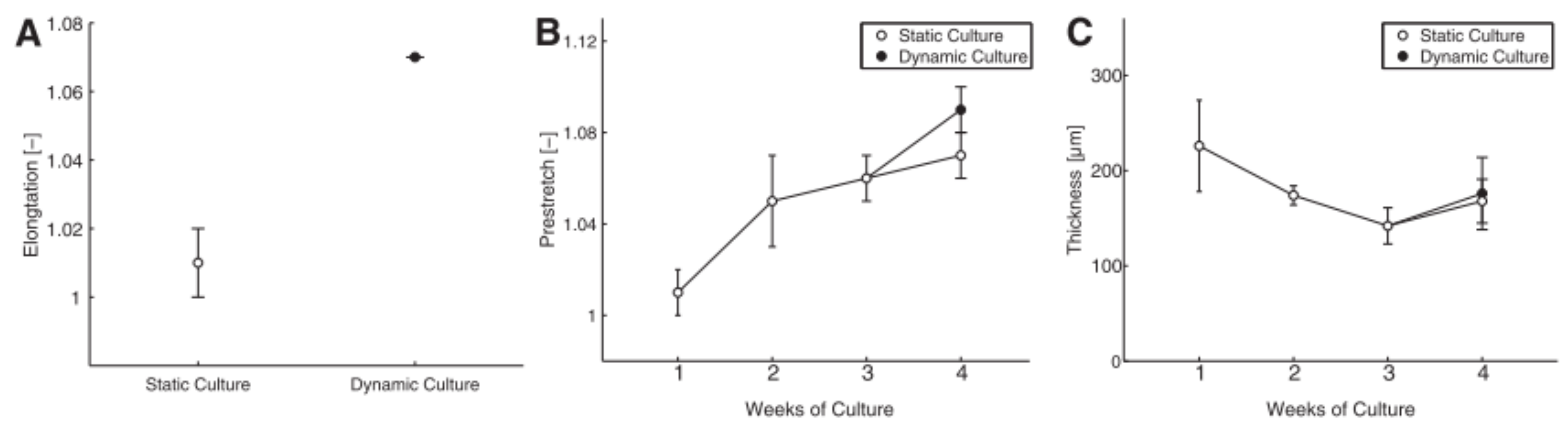

FIG. 7. (A) Tissue elongation at 0 pressure at 4 week for statically and dynamically cultured samples; (B) prestretch development in the TE construct; and (C) Thickness $(\mu \mathrm{m})$ development of the TE constructs during culture. All data is represented as mean value of all samples on the specific timepoint \pm SEM.

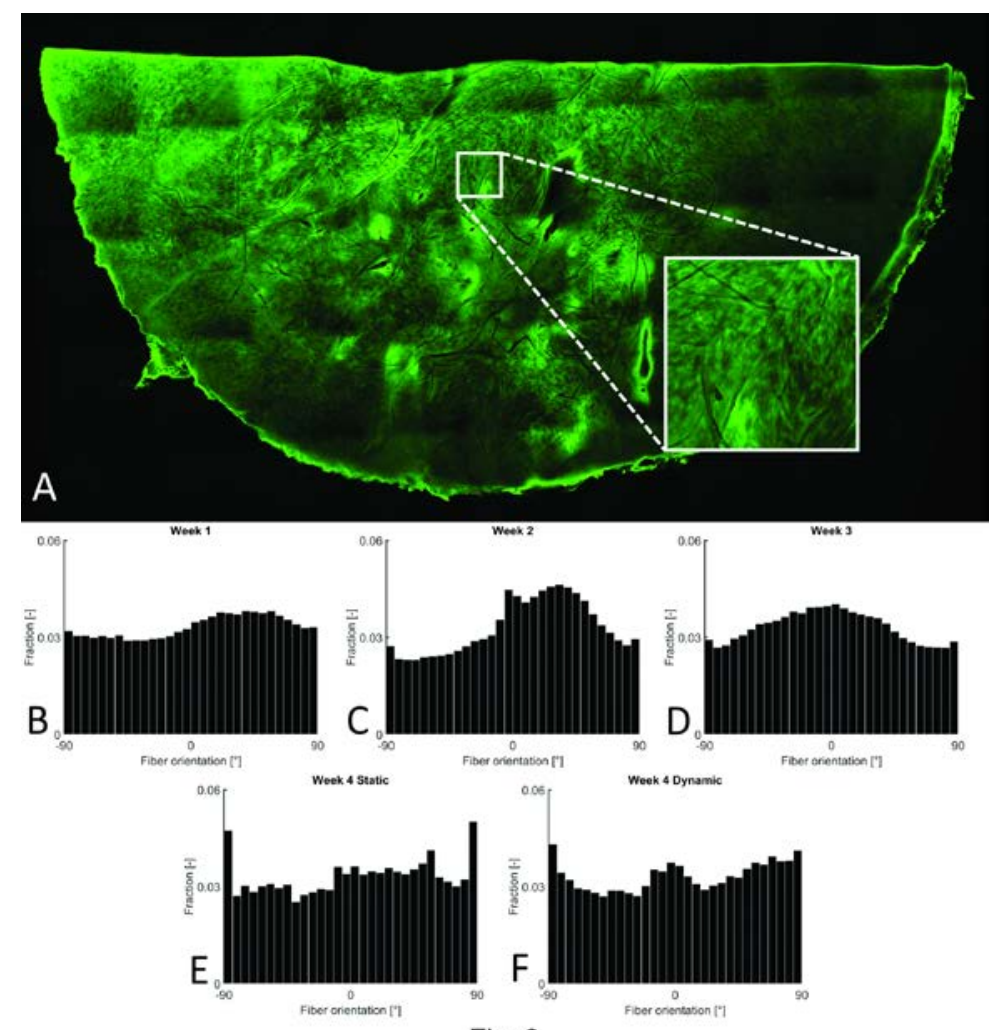

Fig. 8

FIG. 8. (A) Representative CNA stained sample showing the directionality of the collagen fibers. This particular sample was culture statically for 2 weeks, where the collagen was stained in green. (B-F) Histograms showing collagen fiber fractions for each orientation for the entire sample. 


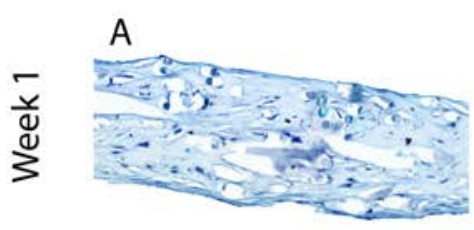

$\mathrm{F}$

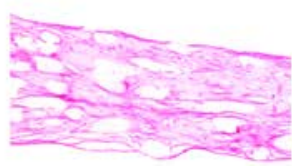

B
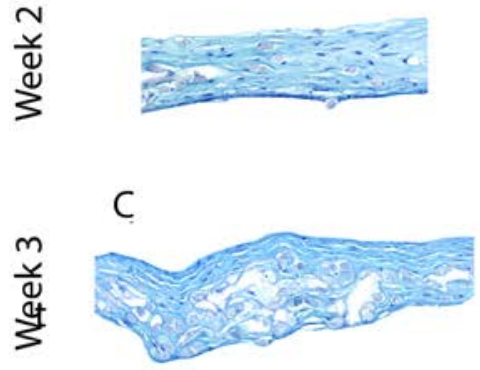

D
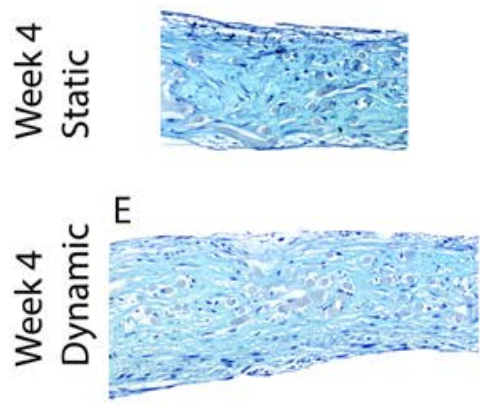

G

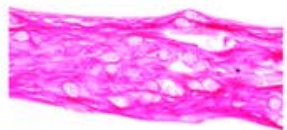

$\mathrm{H}$

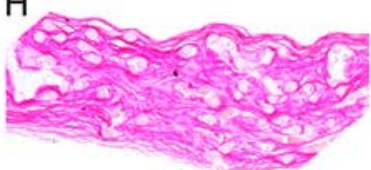

I

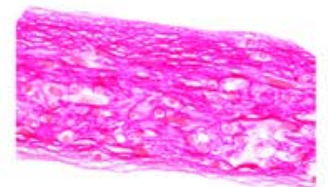

J

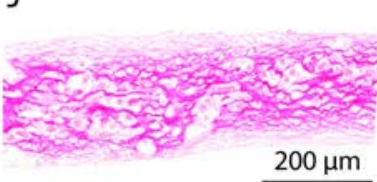

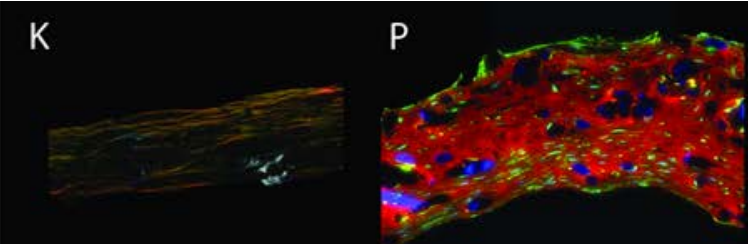

$\mathrm{L}$

Q

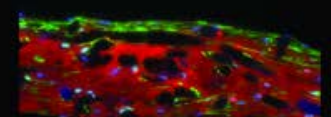

M R

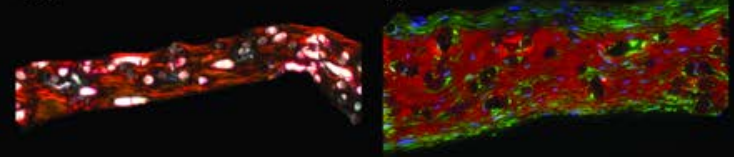

$N$

S

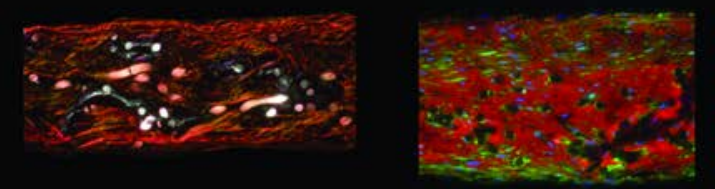

O T

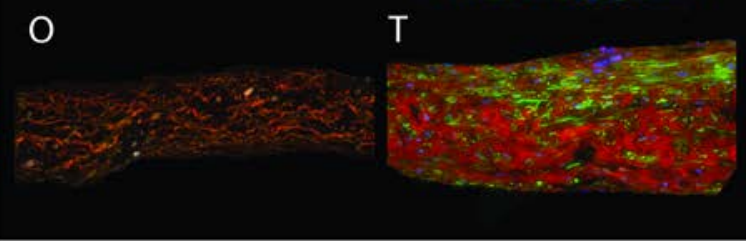

Fig. 9

FIG 9. Representative histology images from all weeks (week 1-4 on the first 4 rows, the final row represents the dynamically cultured samples at week 4). (A-E) AB, (F-J) brightfield PR, (K-O) polarized light PR, and (P-T) fluorescence immuno-staining for collagen (red), cell nuclei (blue) and $\alpha$ SMA (green). Scaffold remnants appear in bright white due to white light reflections (K-O). 

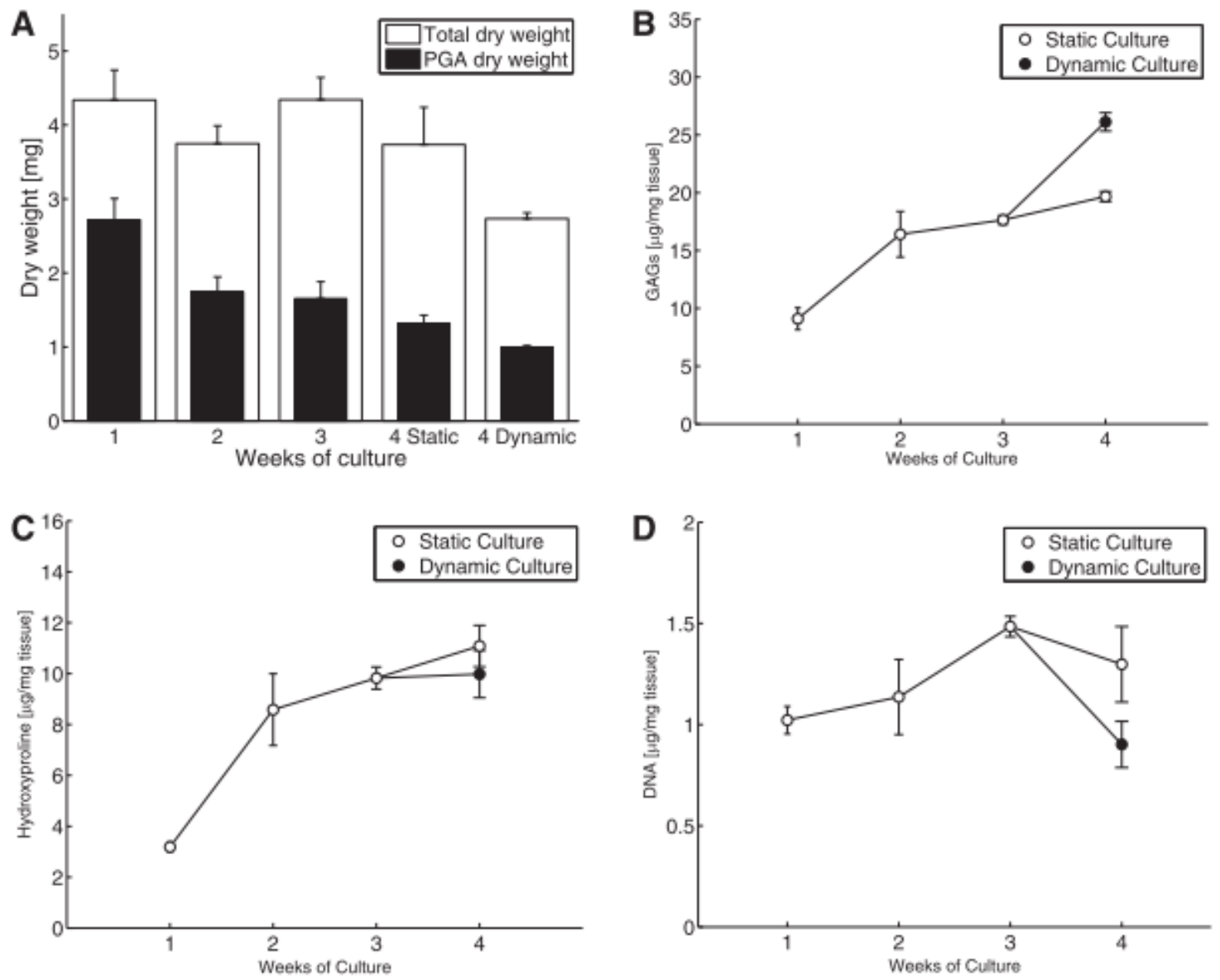

FIG. 10. Biochemical assays. (A) Mean total tissue dry weight (white bars), where the black bars indicate the remaining part of the total weight composed of PGA scaffold. Dry weight concentration of GAGs (B), Hydroxyproline (C) and DNA (D) for the statically and dynamically cultured samples. 